\title{
Rumination in major depressive disorder is associated with impaired neural activation during conflict monitoring
}

\author{
Brandon L. Alderman ${ }^{1 *}$, Ryan L. Olson 1,2, Marsha E. Bates ${ }^{3}$, Edward A. Selby, \\ Jennifer F. Buckman³, Christopher J. Brush'1, Emily A. Panza ${ }^{4}$, Amy Kranzler $^{4}$, \\ David Eddie ${ }^{3}$ and Tracey J. Shors ${ }^{5}$
}

\begin{abstract}
'Department of Exercise Science and Sport Studies, Rutgers, The State University of New Jersey, New Brunswick, NJ, USA, ${ }^{2}$ Department of Nutritional Sciences, Rutgers, The State University of New Jersey, New Brunswick, NJ, USA, ${ }^{3}$ Center of Alcohol Studies, Rutgers, The State University of New Jersey, New Brunswick, NJ, USA, ${ }^{4}$ Department of Psychology, Rutgers, The State University of New Jersey, New Brunswick, NJ, USA, ${ }^{5}$ Department of Psychology, Center for Collaborative Neuroscience, Rutgers, The State University of New Jersey, New Brunswick, NJ, USA
\end{abstract}

OPEN ACCESS

Edited by: Klaus Gramann, Berlin Institute of Technology, Germany

Reviewed by: Jin Fan,

Queens College of the City University of New York and Icahn School of Medicine at Mount Sinai, USA

Tracy L. Luks,

University of California,

San Francisco, USA

*Correspondence:

Brandon L. Alderman, Department of Exercise Science and Sport Studies, Rutgers, The State University of New Jersey, 70 Lipman Drive, New Brunswick, NJ 08901,

alderman@rutgers.e

Received: 05 January 2015 Accepted: 24 April 2015 Published: 12 May 2015

Citation: Alderman BL, Olson RL, Bates ME, Selby EA, Buckman JF, Brush CJ, Panza EA, Kranzler A, Eddie D and Shors TJ (2015) Rumination in major depressive disorder is associated with impaired neural activation during conflict monitoring.

Front. Hum. Neurosci. 9:269. doi: 10.3389/fnhum.2015.00269
Individuals with major depressive disorder (MDD) often ruminate about past experiences, especially those with negative content. These repetitive thoughts may interfere with cognitive processes related to attention and conflict monitoring. However, the temporal nature of these processes as reflected in event-related potentials (ERPs) has not been well-described. We examined behavioral and ERP indices of conflict monitoring during a modified flanker task and the allocation of attention during an attentional blink (AB) task in 33 individuals with MDD and 36 healthy controls, and whether their behavioral performance and ERPs varied with level of rumination. N2 amplitude elicited by the flanker task was significantly reduced in participants with MDD compared to healthy controls. Level of self-reported rumination was also correlated with N2 amplitude. In contrast, P3 amplitude during the AB task was not significantly different between groups, nor was it correlated with rumination. No significant differences were found in behavioral task performance measures between groups or by rumination levels. These findings suggest that rumination in MDD is associated with select deficits in cognitive control, particularly related to conflict monitoring.

Keywords: depression, cognitive control, anterior cingulate cortex, dorsolateral prefrontal cortex, N2, P3

\section{Introduction}

Major depressive disorder (MDD) is one of the most common mental health disorders in the United States with a lifetime prevalence of $\sim 16.6 \%$ (Kessler et al., 2005). Globally, more than 350 million people suffer from depression, and by 2020 it is predicted to be the second largest cause of disability, for all ages and both sexes (Mathers et al., 2008). MDD is characterized by a number of behavioral, emotional, and cognitive symptoms, including psychomotor agitation or retardation, insomnia or hypersomnia, decreased or increased appetite, fatigue, feelings of guilt and worthlessness, and suicidal ideation (American Psychiatric Association, 2000). Other hallmark symptoms include rumination, wherein individuals retrieve and repetitively rehearse autobiographical and negatively valenced content about past and current problems, and attentional problems associated 
with an inability to focus, concentrate, or sustain attention (American Psychiatric Association, 2000; Davidson et al., 2002). These latter symptoms are indicative of deficits in cognitive functioning, which may further contribute to disability and poor quality of life (Holmes and Pizzagalli, 2008; Hammar and Ardal, 2009; Gotlib and Joormann, 2010).

Rumination is one of the most problematic cognitive symptoms associated with depression. These negative thought processes heighten negative affect and interfere with an individual's ability to engage in effective problem-solving and adaptive behaviors (Nolen-Hoeksema et al., 1999; McLaughlin et al., 2007; Nolen-Hoeksema et al., 2008). A number of studies suggest that MDD is associated with impairments in cognitive control processes, specifically those involved in regulating conflict (Lemelin et al., 1997; Davidson et al., 2002; Vanderhasselt et al., 2012; Clawson et al., 2013). In general, cognitive control reflects a person's ability to flexibly and voluntarily regulate behavior or thoughts in the service of goal-directed and purposive behaviors while resisting the retrieval and distraction of competing undesirable information (Miller, 2000; Miller and Cohen, 2001; Aron, 2007). Although less well-studied, recent studies also suggest that excessive rumination, as is often found in individuals with MDD, is associated with less cognitive control (Joormann et al., 2006; Whitmer and Banich, 2007). These control processes are involved in many aspects of healthy cognition and may be involved in delay of gratification and impulse control, as well as self-reflection and the intrusion of negative thought patterns. Structural and functional neuroimaging studies implicate prefrontal and anterior cingulate brain regions in cognitive control (Davidson et al., 2002; van Veen and Carter, 2002; Wagner et al., 2006; Holmes and Pizzagalli, 2008). However, the temporal dynamics of conflict monitoring and cognitive control are not well-described, especially as they relate to rumination.

According to the conflict monitoring hypothesis (Botvinick et al., 2001, 2004; Yeung et al., 2004), an essential aspect of cognitive control involves conflict monitoring and conflict detection, both of which are believed to involve important connections between the anterior cingulate cortex (ACC) and lateral prefrontal regions. Several laboratory-based assessments including the go/no-go, stop signal, antisaccade, Stroop, and flanker interference tasks have been used to manipulate and assess conflict monitoring and cognitive control. The flanker interference task represents a canonical example of this response conflict, such that the presence of competing responses associated with the incongruent condition results in impaired performance relative to the congruent task conditions. Successful performance on this task, particularly on the more challenging trials where the flanking arrows are incongruent with the target arrow, requires greater top-down cognitive control. That is, the incongruent task condition requires competition at the level of response activation and a person's ability to suppress inappropriate or prepotent responses. Task performance deficits have been reported in a number of clinical populations in which disturbances in conflict and response monitoring are present, such as schizophrenia, depression, and substance use disorders (van Veen and Carter, 2002; Pizzagalli, 2011). Functional magnetic resonance imaging
(fMRI) and event-related brain potential (ERP) studies suggest a critical role of the ACC in detecting and evaluating conflicts as they emerge during the action selection process, and using this information to signal for increased recruitment of cognitive control from lateral PFC regions (Botvinick et al., 1999, 2001; van Veen and Carter, 2002; Yeung et al., 2004). The N2 ERP component has been instrumental in studying ACC-mediated conflict monitoring in cognitive control and has also been used to study frontocingulate dysfunction in depression. The conflict N2 (sometimes referred to as flanker N2) is a negative deflection in the stimulus-locked ERP with a frontocentral scalp distribution that peaks $\sim 200-350 \mathrm{~ms}$ after stimulus presentation (Botvinick et al., 2004; Folstein and Van Petten, 2008; Clawson et al., 2013). As an index of conflict processing, this ERP component has been shown to be more negative (i.e., larger) for incongruent flanker trials as a result of conflict that arises during response selection between the responses queued by the target stimulus and those queued by the incompatible flanking stimuli (Yeung et al., 2004; Clawson et al., 2013). This response conflict can also be measured behaviorally, and it has consistently been shown that incongruent or conflicting task conditions result in impaired accuracy and increased reaction time relative to congruent task conditions (Yeung et al., 2004; Tillman and Wiens, 2011; Larson et al., 2014).

Previous research examining conflict monitoring processes and the N2 in MDD has been mixed (Kaiser et al., 2003; Bruder et al., 2012). For instance, Ruchsow et al. (2008) examined N2 and P3 ERP components elicited by a hybrid flanker go/no-go task where participants responded to the appearance of letters $\mathrm{B}$ or $\mathrm{U}$ as centrally located flanker stimuli ("go" condition) and withheld a response to the appearance of letters D or V. Although individuals with MDD evidenced reduced ("less positive") no-go P3 amplitudes compared to matched healthy controls, no between group differences were noted for the N2 component. Similarly, no between-group differences in response time, error rate, or N2 indices of conflict adaptation were found between 55 individuals diagnosed with MDD and demographically similar control participants using a modified flanker task (Clawson et al., 2013). Although no between group differences were found in conflict adaptation, a cognitive control process involving the influence of previous trial congruency on current-trial performance, higher depressive symptom scores based on the BDI-II were associated with smaller mean N2 conflict adaptation scores for individuals with MDD, suggesting that N2 conflict adaptation may be associated with depressive symptoms rather than a clinical diagnosis per se. Alternatively, using an auditory go/no-go task, Kaiser et al. (2003) reported a reduction of inferior frontotemporal positivity in the N2 latency range (i.e., polarity-inverted N2) among patients with unipolar depression. This was interpreted to reflect a specific deficit in the response inhibition component of executive control, and was accompanied by impaired behavioral task performance during the no-go task condition. Differences in the specific tasks used, clinical characteristics of MDD participants, or medication status may have contributed to the mixed findings in the literature. However, the relation between N2 amplitude indices of conflict monitoring and cognitive control and maladaptive rumination remains to be studied. 
In addition to deficits in conflict monitoring, individuals with MDD often experience a selective loss of attention and/or attentional inflexibility (Hammar and Ardal, 2009; Lyche et al., 2011), which may impair their ability to multitask, maintain conversations, and ignore distractions. These problems, in turn, often lead to impaired focus and forgetfulness (Ravnkilde et al., 2002). Several studies have demonstrated attentional deficits in individuals with MDD using a variety of attention-related neuropsychological measures (Cohen et al., 2001; Hammar et al., 2003; Lyche et al., 2011). However, there is some inconsistency across studies. Ottowitz et al. (2002) published a review suggesting that the evidence for selective deficits in attention in MDD was equivocal. Indeed, less than half of the studies (44\%) included in the review demonstrated attentional impairments in MDD. The lack of consistent findings may have been due to variability in study designs, subtyping of depression (e.g., melancholic versus atypical depression), or may simply reflect the multifaceted nature of attention. That is, MDD may impair only select aspects of attention, and these impairments may be best characterized by tests specifically designed to evaluate a particular component of attention (Ottowitz et al., 2002). Further, rumination may contribute to many of the cognitive biases and impairments found in MDD, including deficits found in attentional processes (Donaldson et al., 2007), but this suggestion has received only limited research attention.

Attentional processes in the brain depend on finely timed sequences that result in the allocation of attentional resources for perception and processing of sensory stimuli across time. One approach that has been used to probe the temporal dynamics of attention is the rapid serial visual presentation (RSVP) paradigm and the attentional blink $(\mathrm{AB})$ phenomenon (Raymond et al., 1992). First described in 1992, the AB is typically observed during RSVP tasks whereby individuals exhibit a reduced ability to report the second (T2) of two different target stimuli presented among a very rapid stream of visual distractors when T2 appears within $\sim 100-500$ ms of the first target (T1; Broadbent and Broadbent, 1987; Raymond et al., 1992). Although no current theoretical explanations fully account for this phenomenon (Dux and Marois, 2009), most point to a limited capacity attentional resource system, indicating that sensory information is not transferred efficiently from early sensory processing stages (and brain regions) to those involved in working memory (Luck et al., 1996; Martens et al., 2002). The magnitude of the AB (i.e., the time it takes to recognize $\mathrm{T} 2$ following presentation of $\mathrm{T} 1$ ) has been shown to be larger in clinical populations (Husain et al., 1997; Husain and Rorden, 2003), the elderly (Lahar et al., 2001; Maciokas and Crognale, 2003), and children with attentiondeficit/hyperactivity disorder (Hollingsworth et al., 2001; Li et al., 2004). Neuroimaging evidence suggests an interactive neural network consisting predominantly of overlapping lateral-frontal, inferotemporal, posterior-parietal, and occipital brain regions underlying the AB response (Marois and Ivanoff, 2005; Hommel et al., 2006).

For the $\mathrm{AB}$ paradigm, we assessed the classic cognitive P3 ERP component, which is thought to reflect the allocation of attentional resources during the updating of working memory (Donchin and Coles, 1988; Polich, 2007). Previous studies have demonstrated a completely suppressed P3 but no change in amplitude or latency for earlier ERP components (e.g., P1, N1, $\mathrm{N} 400$ ), when the $\mathrm{AB}$ phenomenon occurs. These findings suggest that the $\mathrm{AB}$ occurs after early perceptual processing is complete. It also has been speculated that the blink response may reflect a failure to input or consolidate the second stimulus (T2) into working memory while $\mathrm{T} 1$ is being processed (Luck et al., 2000), thus supporting the utility of the P3 in documenting this effect. Consequently, the $\mathrm{AB}$ paradigm may help to elucidate the temporal nature of attention deficits in MDD and explain how select attentional processes are influenced by rumination levels. Although the $\mathrm{P} 3$ component in MDD has received scant attention using the RSVP paradigm, in general depressed patients show some reduction of the parietally maximal P3 component using a variety of oddball and go/no-go tasks (Bruder et al., 2012).

The present study used the flanker task and the RSVP paradigm to examine the relationship of rumination to response conflict and the temporal dynamics of attention in individuals diagnosed with MDD compared to healthy controls. Although recognizing the lack of agreement in the literature concerning the $\mathrm{N} 2$ potential in MDD, we hypothesized that individuals with a current diagnosis of depression would display relative deficits in conflict monitoring using a modified flanker task. We expected these deficits to manifest as reductions in N2 amplitude as well as impaired behavioral task performance outcomes. It was also hypothesized that individuals with MDD would exhibit selective deficits in attention (i.e., evidence a larger blink) during the rapid presentation of visual stimuli and larger T1- and T2-elicited P3 amplitudes. These findings would indicate that individuals with MDD have less efficient neural resource allocation, resulting in impaired ability to consolidate two temporally close items into working memory. It was predicted that individual differences in rumination would covary with both ERP and behavioral deficits in the performance of both tasks.

\section{Materials and Methods}

\section{Participants}

Individuals with MDD were solicited from a university counseling and psychiatric services clinic, where they were diagnosed prior to participation by a psychologist, psychiatrist, or primary care provider. Control participants were recruited through advertisements posted in numerous locations around the university campus and local community. Recruitment was for a mental and physical skill training program aimed at improving physical and psychological health; the data presented herein represent findings from the initial baseline assessment. Participants of all ethnic origins between 18 and 35 years of age were included in the study. Only right-handed participants with normal or corrected-to-normal vision were included in the current analyses. Participants in the MDD group were included if they met diagnostic (DSM-IV-TR) criteria for current MDD (American Psychiatric Association, 1994) and confirmed by the MiniInternational Neuropsychiatric Interview (MINI; Sheehan et al., 1998). Exclusion criteria included a diagnosis of a bipolar spectrum disorder, schizophrenia spectrum disorder, self-injurious or 
suicidal behavior, or a history of neurological disorders or head injuries resulting in a loss of consciousness. All clinical interviews and suicide risk assessments were completed by trained graduate students working with the study PIs, and all were trained to competence by a licensed clinical psychologist (EAS), who supervised all study clinical assessments and is a member of the clinical psychology Ph.D. training program at Rutgers University. Prior to participating in clinical interviews, all clinical interviewers completed extensive clinical training regarding the clinical symptoms assessed with the MINI, including depression. This training included formal team meetings outlining the structure and content of the diagnostic interview, discussions on troubleshooting and differential diagnoses with the interview, extensive shadowing of Dr. Selby who completed all assessments during the first semester of data collection, and an examination interview that required rating the correct diagnoses for a case presenting pre-specified symptoms that all interviewers were required to pass. During the course of the study any concerns regarding diagnostic symptom endorsement or suicide risk concerns were discussed with the supervisor to ensure patient risk protection. The MINI is an appropriate tool for assigning threshold level psychiatric diagnoses in research settings and has been found to have strong diagnostic agreement with other clinical interviews such as the Structured Clinical Interview for DSM-IV Axis I Disorders (SCID; First et al., 1995), which are frequently used in clinical settings because they explore symptoms in more depth than is needed for a research study (Jones et al., 2005). Healthy comparison participants who did not meet criteria for MDD via the MINI were also recruited and included if they reported no previous or current history of neuropsychiatric disorders, neurological disorders, or head injuries. All eligible individuals were invited to visit the laboratory for a more extensive clinical interview and neurophysiological testing. The final sample consisted of 33 MDD participants and 36 healthy controls. MDD and control participants did not differ with respect to age, sex, ethnicity, or educational level, $p s>0.05$. Six of the 33 MDD (18\%) participants had a confirmed comorbid diagnosis at the time of participation [one with post-traumatic stress disorder, five with generalized anxiety disorder (GAD)] and three of these participants reported current antidepressant drug use. Additionally, two other participants were currently taking either antidepressant $(n=1)$ or ADHD $(n=1)$ medication. No medication use was reported among the control participants. As expected, MDD participants reported significantly increased levels of depressive symptoms assessed by the Beck Depression Inventory-II (BDIII; Beck et al., 1961, 1996) and rumination as assessed by the Ruminative Responses Scale (RRS; Nolen-Hoeksema et al., 1999). Table 1 shows participants' demographic and behavioral data according to group status. The research protocol was approved by the university's Institutional Review Board and written informed consent was obtained from all participants prior to participation.

\section{Procedures}

Individuals meeting the initial study inclusion criteria were invited for a baseline testing session to complete a clinical interview and provide behavioral and neurophysiological data. After receiving a general description of the study and providing written
TABLE 1 | Demographic and clinical characteristics of participants by group status.

\begin{tabular}{llll}
\hline Characteristic & Control & MDD & Total \\
\hline$n$ & 36 & 33 & 69 \\
Age (years) & $21.0 \pm 3.1$ & $20.7 \pm 2.9$ & $20.9 \pm 2.9$ \\
Gender (male/female) & $12 / 24$ & $9 / 24$ & $21 / 48$ \\
Height (cm) & $166.6 \pm 8.5$ & $164.9 \pm 7.9$ & $165.8 \pm 8.2$ \\
Weight (kg) & $67.4 \pm 15.0$ & $66.3 \pm 15.6$ & $66.9 \pm 15.2$ \\
BMl (kg/m²) & $24.3 \pm 5.1$ & $24.3 \pm 4.9$ & $24.3 \pm 5.0$ \\
BDI-Il score & $7.4 \pm 4.8$ & $23.9 \pm 8.3^{*}$ & $15.4 \pm 10.7$ \\
RRS total & $41.9 \pm 10.6$ & $59.1 \pm 10.2^{*}$ & $50.2 \pm 13.5$ \\
$\quad$ Depression & $21.8 \pm 5.9$ & $33.2 \pm 6.6^{*}$ & $27.3 \pm 8.4$ \\
$\quad$ Brooding & $9.7 \pm 2.5$ & $13.5 \pm 3.6^{*}$ & $11.5 \pm 3.6$ \\
$\quad$ Reflection & $10.4 \pm 3.9$ & $12.4 \pm 3.2^{*}$ & $11.4 \pm 3.7$ \\
\hline
\end{tabular}

Values equal mean $\pm S D$. MDD, major depressive disorder; BMI, body mass index; BDI, Beck Depression Inventory; RRS, Ruminative Responses Scale. Asterisks indicate statistically significant unpaired student's t-test between control and MDD participants, $p<0.05$.

informed consent, participants completed a set of questionnaires pertaining to their demographics, attitudes, mood, and health, including the BDI-II and RRS. Next, participants were fitted with a 64-channel Geodesic Sensor Net (Electrical Geodesics, Inc., Eugene, OR, USA) and seated $\sim 0.5 \mathrm{~m}$ directly in front of a 17 ” Dell computer monitor. After completing a 5-min rest period, participants completed the flanker and $\mathrm{AB}$ tasks in counterbalanced order. Following the neurocognitive assessments, participants completed a cardiovascular and physical fitness test battery that was part of the larger intervention study.

\section{MDD Diagnosis, Depression Symptoms, and Rumination Assessment Mini Neuropsychiatric Diagnostic Interview}

The MINI (manic/hypomanic episodes, obsessive-compulsive disorder, substance and alcohol use disorders) was used to confirm clinical diagnosis of MDD. The MINI is a brief structured interview that has been used extensively to aid in making diagnoses of Diagnostic and Statistical Manual of Mental Disorders, Fourth Edition (DSM-IV) and International Classification of Diseases-10 (ICD-10) psychiatric disorders. The reliability and validity of this instrument have been previously established (Lecrubier et al., 1997; Sheehan et al., 1997). The point biserial correlation coefficient of MDD diagnosis with BDI-II scores was $0.80, p<0.001$.

\section{Depressive Symptoms}

Participants completed the BDI-II (Beck et al., 1961), a 21-item, self-report inventory of the severity of current depressive symptoms. Higher total scores reflect greater subjectively perceived depressive symptomatology. The BDI-II in this sample demonstrated good internal consistency $(\alpha=0.92)$.

\section{Rumination}

Participants completed the RRS (Nolen-Hoeksema et al., 1999), which includes 22 items describing thoughts and responses to depressed mood that are focused on the individual themselves, possible symptoms, and potential consequences/causes of the 
mood. They were asked to rate each item on a scale from 1 (almost never) to 4 (almost always). An example of one of the items is: "Analyze recent events to try to understand why you are depressed." The RRS scale demonstrated appropriate internal consistency $(\alpha=0.93)$.

\section{Cognitive Tasks \\ Eriksen Flanker}

A modified arrow version of the Eriksen flanker task (Eriksen and Eriksen, 1974) was presented with E-prime version 2.0 software (Psychology Software Tools, Inc., Pittsburgh, PA, USA). The flanker task is composed of two conditions, congruent and incongruent, during which participants are asked to press a button corresponding to the direction of a centrally positioned target arrow (see Figure 1). The congruent trials consisted of the target arrow being flanked by arrows facing the same direction (i.e., $<<<<$ or $\rangle>\rangle\rangle\rangle$ ), while incongruent trials involved the target arrow being flanked by arrows facing the opposing direction (i.e., $<<><<$ or $>><>>$ ). A set of instructions preceded the first trial that explained which button press would be used to indicate the direction of the central or target arrow. Participants performed a button press with their left thumb when the target arrow, or third arrow from the left, pointed to the left $(<)$ and a button press with their right thumb when the target arrow pointed to the right $(>)$. Following task instructions, participants completed 20 practice trials. Performance feedback was provided on the computer screen and any remaining questions were answered during the practice trials to ensure participants sufficiently understood the task. Each trial began with a black screen containing a white fixation cross $(+)$ in the middle of the screen for $500 \mathrm{~ms}$, following which $7.6 \mathrm{~cm}$ tall stimuli were presented focally on a computer screen in white letters on a black background for $100 \mathrm{~ms}$ with a response window of $1500 \mathrm{~ms}$ and a variable inter-stimulus interval (ISI) of 1100, 1300, or $1500 \mathrm{~ms}$. Participants were instructed to respond as quickly and accurately as possible for each trial. Two blocks of 110 trials were

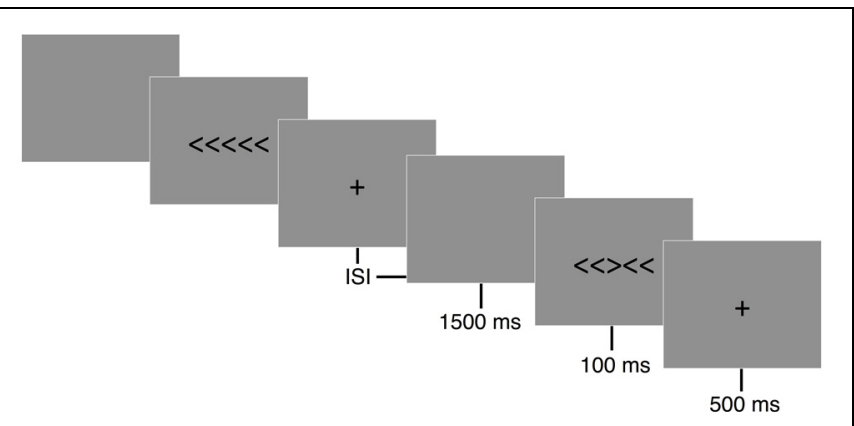

FIGURE 1 | Eriksen flanker task. Following a $500 \mathrm{~ms}$ fixation cross (+), either congruent $(<<<<<)$ or incongruent $(<<><<)$ stimuli were displayed focally for $100 \mathrm{~ms}$ on a computer screen. Participants were instructed to respond to the direction of a centrally positioned target arrow as quickly and accurately as possible. A button press corresponding to the direction of the centrally positioned arrow was recorded during a $1500 \mathrm{~ms}$ response window. A random inter-stimulus interval (ISI) of 1100, 1300, or 1500 ms occurred following the participant's response to reduce expectancy effects. administered with equiprobable congruency and directionality of stimuli.

\section{Attentional Blink}

A modified version of the $\mathrm{AB}$ task was adapted from Slagter et al. (2007) and used to assess competition between targets for limited attentional resources (Shapiro et al., 1997; Martens and Wyble, 2010). Stimuli were presented focally on a computer screen in white letters on a black background. Following the presentation of a 1780 ms fixation cross (+), a RSVP of 15 or 19 capital letters was presented. Participants were instructed to identify two target numbers (T1 and T2) embedded within the rapid visual stream of letters (distractors). Each stimulus was presented for $50 \mathrm{~ms}$, followed by a 34-ms blank slide (Figure 2). For each trial, the letter (distractor) was randomly selected (without replacement) from the alphabet. Within each trial, one (single-target) or two (dual-target) letters were replaced with a randomly drawn (without replacement) number ranging from 2 to 9. In the case of single-target trials, the second target was replaced with a blank screen (T2-absent trial). The time between T1 and T2 (or the blank) was either $336 \mathrm{~ms}$ (short) or $672 \mathrm{~ms}$ (long). The shorter timeframe between targets (T2-present/short trials) has been shown to reliably produce a blink (misidentified T2) compared to the longer timeframe (T2-present, long trials). This occurs during peak competition for limited attentional resources (Slagter et al., 2007). T2 and the blank screen were presented in positions 3-5 from the end of the stream. Due to similarities, letters B, I, O, Q, and $S$ and numbers 1 and 0 were omitted from the visual stream.

Prior to the task, participants were instructed that there could be one or two numbers (targets) in the letter stream. At $1000 \mathrm{~ms}$ after the stream was completed, participants were instructed to enter the numbers on a keyboard in the order they were presented. If participants were unable to identify $\mathrm{T} 2$, they were instructed to guess its identity. Participants entered zero if they were absolutely certain there was no second target presented. A new trial began $200 \mathrm{~ms}$ after the second number (or blank) was identified. In addition to verbal instructions, on-screen instructions and a 1-min practice block, with feedback, were provided prior to actual testing. Participants then performed two blocks of 112 trials each. There were a total of $116 \mathrm{~T} 2$-present/short trials, $36 \mathrm{~T} 2$-present/long trials, $36 \mathrm{~T} 2$-absent/short trials, and 36 $\mathrm{T} 2$-absent/long trials, which were randomly selected during each block.

\section{ERP Data}

Electroencephalographic (EEG) activity was recorded using a 64channel Geodesic Sensor Net system (Electrical Geodesics, Inc., Eugene, OR, USA) arranged according to the International 1010 system (Chatrian et al., 1988). The electrooculogram (EOG) was recorded from electrodes located above and below each eye. Individual electrode impedances were kept below $50 \mathrm{k} \Omega$ in accordance with standard data collection procedures (Ferree et al., 2001). Although lower impedances are typically recommended (Luck, 2014), previous research has shown excellent EEG signals when data were collected with higher scalp impedance (Ferree et al., 2001; Keil et al., 2014), and similar values have been used in the study of ERP components in MDD (Clawson et al., 


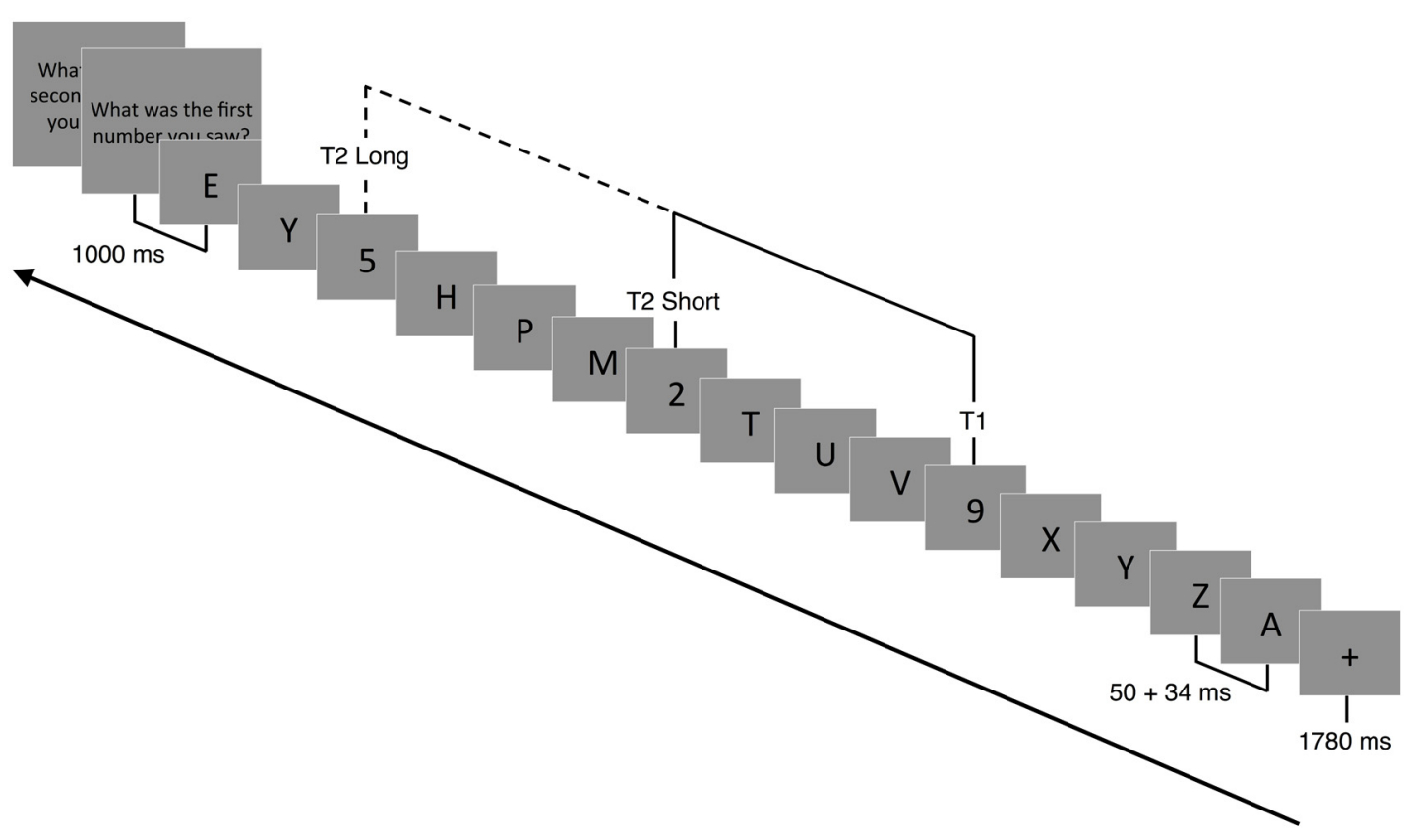

FIGURE 2 | Attentional blink paradigm. Following a $1780 \mathrm{~ms}$ fixation cross (+), a RSVP of 15 or 19 capital letters (distractors) were displayed focally on a computer screen. Embedded within the RSVP were 1 (T1 present-T2 absent) or 2 (T1 present-T2 present) target numbers. Each slide was presented for $50 \mathrm{~ms}$ followed by a 34 ms blank slide. Participants had to detect T1 and T2 (if present) and report their response at the end of each trial. In T2 absent trials, T2 was replaced with a blank screen. The temporal lag between T1 and T2 could vary between $336 \mathrm{~ms}$ (short trials) and $672 \mathrm{~ms}$ (long trials).
2013). Data were sampled at $250 \mathrm{~Hz}$ and collected with a $0.1-$ $100 \mathrm{~Hz}$ bandpass hardware filter. Continuous data were recorded during each task condition referenced to the vertex electrode $(\mathrm{Cz})$. Following collection, data were re-referenced (Bertrand et al., 1985; Tucker et al., 1994) to the mastoids and filtered with a $35 \mathrm{~Hz}$ low-pass filter. Data were visually inspected for eyeblinks, eye-movements, and bad channels before and after artifact rejection tools were applied to correct and remove ocular artifact using NetStation 4.0 (Electrical Geodesics, Inc., Eugene, OR, USA). Briefly, segments were marked "bad" if they contained (1) eye movements exceeding $55 \mu \mathrm{V}$, (2) eye blinks exceeding $140 \mu \mathrm{V}$, or (3) greater than or equal to 10 bad channels exceeding $200 \mu \mathrm{V}$. In each case, a moving average of 20 samples combined with threshold values were used. Using spherical spline interpolation, bad channels were then replaced from the remaining channels in "good" segments.

For the flanker task, epochs of individual trials were created from $100 \mathrm{~ms}$ pre- to $1000 \mathrm{~ms}$ post-stimulus presentation and baseline adjusted using the $100 \mathrm{~ms}$ pre-stimulus period. ERPs were constructed by averaging across congruent and incongruent trials separately for each participant. N2 amplitude was captured using a mean-amplitude approach. Consistent with previous research and based on visual inspection of waveforms (Krompinger and Simons, 2011; Keil et al., 2014; Luck, 2014), we used a window spanning 200-350 ms post-stimulus to evaluate the N2 (Folstein and Van Petten, 2008; Dickter and Bartholow, 2010). For the AB task, epochs of individual trials were created from $200 \mathrm{~ms}$ pre- to $2000 \mathrm{~ms}$ post-stimulus (relative to T1). All epochs were baseline corrected using the $200 \mathrm{~ms}$ pre-stimulus period. For short trials, the T1-elicited P3 components were defined within a $295-365$ ms window post-stimulus, while the T2-elicited P3 components were defined within a $847-1151 \mathrm{~ms}$ window (Slagter et al., 2007). Additionally, on long trials, T1elicited P3 components were averaged across a 295-651 ms window while the T2-elicited P3 components were defined within a 1147-1451 ms window (Slagter et al., 2007). We used a mean amplitude approach to isolate ERP components since this is viewed as a more unbiased estimation of ERP amplitude (Clayson et al., 2013; Luck, 2014). Artifact-free waveforms where the arrow directions were correctly identified (flanker) or both T1 and T2 targets were identified $(\mathrm{AB})$ were subsequently grand averaged.

\section{Data Analysis Behavioral Data}

Only trials in which a response was attempted were considered. To reduce the potential effect of outliers, trials with RTs beyond the individual mean $\pm 3 \mathrm{SD}$ for each trial type were excluded. Exploratory analyses using one-way analyses of variance (ANOVAs) revealed no significant effects of sex or ethnicity on any of the cognitive performance measures; therefore, these variables were not further considered. Behavioral performance data (i.e., response time and accuracy) from the flanker task were submitted to a 2 (Group: MDD patients, controls) $\times 2$ (Task Congruency: Congruent, Incongruent) ANOVA with repeated measures. To assess performance on the AB task, average T1 and T2 accuracy data were submitted to a 2 (Group: MDD patients, controls) $\times 2$ (Lag: Short, Long) ANOVA. Only trials in which T1 was identified correctly were examined. In order to determine 
the relationship between self-reported rumination and behavioral task performance, a bivariate Pearson correlation between rumination scores and accuracy and RT data for both cognitive tasks was performed.

\section{ERP Data}

In light of the frontocentral nature of the $\mathrm{N} 2$ component elicited by the flanker task, a mixed 2 (Group: MDD patients, controls) $\times 2$ (Task Congruency: Congruent, Incongruent) $\times 3$ (Site: $\mathrm{Fz}, \mathrm{FCz}, \mathrm{Cz}$ ) ANOVA with repeated measures was conducted on mean N2 amplitudes. Less negative values were interpreted as reflecting less cognitive control in response to the stimulus. To investigate the relationship between rumination and N2, we performed bivariate Pearson correlations between self-reported rumination scores and N2 amplitudes for congruent and incongruent flanker trials. For the $\mathrm{AB}$ task, mixed 2 (Group: MDD patients, controls) × 2 (Lag: Short, Long) $\times 4$ (Site: $\mathrm{Fz}, \mathrm{FCz}, \mathrm{Cz}, \mathrm{Pz}$ ) with repeated measures were conducted for P3 amplitudes corresponding to T1 and T2. Since previous research indicates that comorbid anxiety-related disorders and psychotropic medications may influence neural activation patterns (Gehring et al., 2000; de Bruijn et al., 2006; Hajcak et al., 2008) and psychomotor speed, we reanalyzed the behavioral and ERP outcomes while excluding those participants with comorbid diagnoses or current psychotropic medication use. We performed similar bivariate correlations for P3 amplitudes on T1 and T2 trials of the AB task. Partial eta squared $\left(\eta_{\mathrm{p}}^{2}\right)$ values are reported to demonstrate the magnitude of effect sizes (ESs) following ANOVAs, with 0.01-0.059 representing a small effect, 0.06-0.139 a medium effect, and $>0.14$ a large effect (Cohen, 1973). Post hoc comparisons were conducted using univariate ANOVAs and Bonferroni corrected $t$-tests. ESs were calculated for any pairwise comparisons by using Hedges' g statistic (Hedges, 1981). A critical alpha level of $p \leq 0.05$ was adopted for all significance tests.

\section{Results}

\section{Behavioral Data}

For accuracy on the flanker task, the mixed 2 (Group) $\times 2$ (Task Congruency) ANOVA revealed a main effect of congruency, $F(1,67)=34.97, p<0.001, \eta_{\mathrm{p}}^{2}=0.34$, indicating that participants performed worse on incongruent relative to congruent trials. No main effect of group or group by congruency interaction was observed, indicating that MDD and healthy controls did not differ in terms of overall accuracy. This test also confirmed that a comparable number of data points in each group were available for subsequent ERP analysis. The ANOVA for RT similarly showed a main effect of congruency, $F(1,67)=397.52$, $p<0.001, \eta_{\mathrm{p}}^{2}=0.86$, due to faster response times for congruent versus incongruent trials. The main effect of group and the group $\times$ congruency interaction were not statistically significant. For the AB task, T2 accuracy was significantly higher on long trials $(74 \%)$ than on short trials $(61 \%), F(1,67)=69.33, p<0.001$, $\eta_{\mathrm{p}}^{2}=0.51$, confirming an AB effect whereby $\mathrm{T} 2$ was detected less frequently on the short trials. However, no significant group main effect or interaction with group was observed. In sum, MDD and healthy control participants did not differ in terms of behavioral task performance for either task (see Figure 3). These findings remained consistent when we reanalyzed the data to account for comorbid diagnoses or current medication use. No significant correlations emerged between self-reported rumination and behavioral performance measures for either cognitive task.

\section{ERP Data}

Figure 4 illustrates the grand averaged ERP waveforms for each group at the three frontocentral midline electrode sites $(\mathrm{Fz}, \mathrm{FCz}$, $\mathrm{Cz}$ ) to congruent and incongruent flanker task stimuli. The total number of flanker trials used for ERP analysis did not differ by group or condition. ERPs for MDD participants included a total of $88 \pm 16$ trials for the incongruent condition and $88 \pm 15$ trials for the congruent condition and ERPs for control participants included a total of $93 \pm 12$ trials for the incongruent condition and $92 \pm 13$ trials for the congruent condition (mean \pm SD). For the N2 component, a Group (MDD, controls) $\times$ Task Congruency (Congruent, Incongruent) $\times$ Site $(\mathrm{Fz}, \mathrm{FCz}, \mathrm{Cz})$ ANOVA revealed a main effect of Group, $F(1,67)=6.28$, $p=0.015, \eta_{\mathrm{p}}^{2}=0.09$, Task Congruency, $F(1,67)=16.48$, $p<0.001, \eta_{\mathrm{p}}^{2}=0.20$, and Site, $F(2,66)=27.63, p<0.001$, $\eta_{\mathrm{p}}^{2}=0.46$. Post hoc Bonferroni corrected $t$-tests of the Group main effect indicated that healthy controls demonstrated overall more negative activity $(0.348 \mu \mathrm{V})$ in the $\mathrm{N} 2$ latency time window than the MDD group $(-1.483 \mu \mathrm{V}), p=0.015$. The Congruency main effect showed that N2 displayed a larger response (more negative amplitude) for incongruent $(-0.967 \mu \mathrm{V})$ relative to congruent $(-0.167 \mu \mathrm{V})$ flanker trials, $p<0.001$. Decomposition of the Site main effect revealed significantly more negative amplitudes for $\mathrm{Fz}(-1.442 \mu \mathrm{V})$ and $\mathrm{FCz}(-1.036 \mu \mathrm{V})$ sites relative to $\mathrm{Cz}(0.777 \mu \mathrm{V}), \mathrm{ps}<0.05$. The Group and Task Congruency main effects were superseded by a significant Group $\times$ Task Congruency interaction, $F(1,67)=4.20, p<0.05, \eta_{\mathrm{p}}^{2}=0.06$. This interaction revealed a larger flanker N2 effect (i.e., larger $\mathrm{N} 2$ for incongruent versus congruent task conditions) for healthy participants $(1.204 \mu \mathrm{V}), \mathrm{ES}=0.38, p<0.001$, compared to MDD participants $(0.396 \mu \mathrm{V}), \mathrm{ES}=0.13, p=0.131$. Significant main effects of Group, Congruency, and the Group $\times$ Task Congruency interaction remained significant when accounting for comorbid diagnosis and current medication use $(F s>3.7$, $p s<0.05)$, suggesting that these differences did not alter the overall pattern of findings. Importantly, self-reported rumination was also significantly correlated with N2 amplitude, $r=0.28, p=0.02$ (see Figure 5). This positive correlation indicates that as rumination scores increased, N2 amplitude became more positive (i.e., less negative $\mathrm{N} 2$ amplitude reflects reduced cognitive control).

Figure 6 illustrates the grand averaged ERP waveforms for each group averaged across the $\mathrm{Cz}, \mathrm{CPz}$, and $\mathrm{Pz}$ midline electrode sites to short and long trials of the $\mathrm{AB}$ task. The total number of $A B$ trials used for ERP analysis did not differ by group or condition. ERPs for MDD participants included a total of $80 \pm 21$ trials for the short lag condition and $23 \pm 5$ trials for the long lag condition. Similarly, ERPs for control participants included a total of $80 \pm 26$ trials for the short lag condition and 

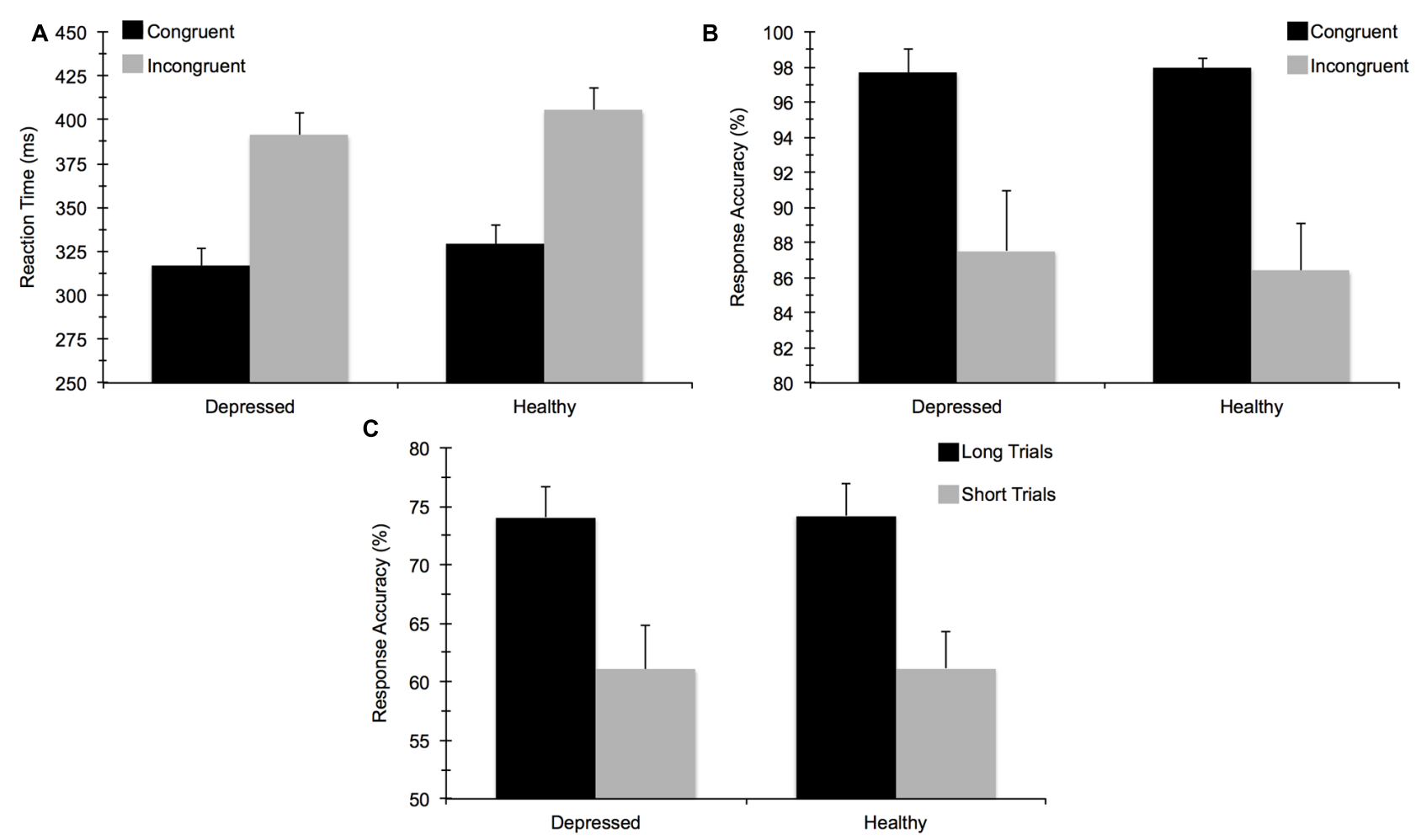

FIGURE 3 | Mean ( \pm ) SE behavioral task performance for: (A) reaction time (ms) on the flanker task, (B) response accuracy (\%) on the flanker task, and $(C)$ response accuracy on the attentional blink task.

$22 \pm 4$ trials for the long lag condition (mean \pm SD). For the $\mathrm{AB}$ task, the omnibus analysis for $\mathrm{P} 3$ amplitude to $\mathrm{T} 1$ yielded a significant main effect for Lag, $F(1,67)=11.25, p<0.001$, $\eta_{\mathrm{p}}^{2}=0.14$, and Site, $F(3,65)=21.79, p<0.001, \eta_{\mathrm{p}}^{2}=0.50$, with post hoc analyses for Lag revealing significantly larger T1elicited P3 amplitudes in long trials compared to short trials and for Site revealing a central-parietal distribution, with the parietal and central sites showing significantly larger amplitudes than the frontal and frontocentral sites, $p s<0.01$. No group level main effects or interactions were evident for T1-elicited P3 amplitude. The 3-way mixed model ANOVA for P3 amplitude elicited by $\mathrm{T} 2$ similarly revealed a significant main effect for Lag, $F(1,67)=19.66, p<0.001, \eta_{\mathrm{p}}^{2}=0.23$, and Site, $F(3,65)=4.75$, $p<0.01, \eta_{\mathrm{p}}^{2}=0.18$, with post hoc analyses revealing larger T2elicited P3 amplitudes on long trials compared to short trials and for Site revealing larger P3 amplitudes over central and parietal electrode sites compared to frontal and frontocentral sites. No significant main effects or interactions by Group were found. Self-reported rumination levels were not associated with T1- or T2-elicited P3 amplitudes for short or long trials $(p>0.05)$.

\section{Discussion}

Individuals who suffer from MDD often experience deficits in learning, memory, selective attention, and cognitive control (Veiel, 1997; Zakzanis et al., 1998; Austin et al., 2001; Hammar and Ardal, 2009). These various processes allow one to initiate actions, evaluate risks, make decisions, plan for the future, inhibit habitual or prepotent responses, and resist temptations. During depressive episodes, individuals often ruminate about the past, which further interferes with cognitive control processes and the ability to inhibit unwanted thought patterns. In this study, we examined conflict monitoring using a modified flanker task and the ability to process two temporally close stimuli using a RSVP paradigm in depressed individuals and healthy controls, as well as the relationship of these cognitive processes to rumination. We examined how these behavioral and psychological measures related to neural indices of cognitive control and attention as evident in ERPs elicited by the flanker and AB tasks. The present findings indicate that although behavioral task performance was comparable between the two groups, there were differences between the groups' respective ERP responses to environmental stimuli. ERPs may be more sensitive to subtle cognitive dysfunction in MDD and provide some insight into the underlying mechanisms involved. Consistent with our hypotheses, the amplitude of the N2 was significantly reduced in depressed participants when compared to non-depressed participants. These neuronal responses were particularly observed in response to the incongruent flanker task condition (i.e., the task condition requiring greater amounts of conflict monitoring) and were maximal at frontocentral recording sites. Moreover, correlation analyses indicated that participants who reported greater rumination levels also expressed significantly smaller N2 amplitudes. 


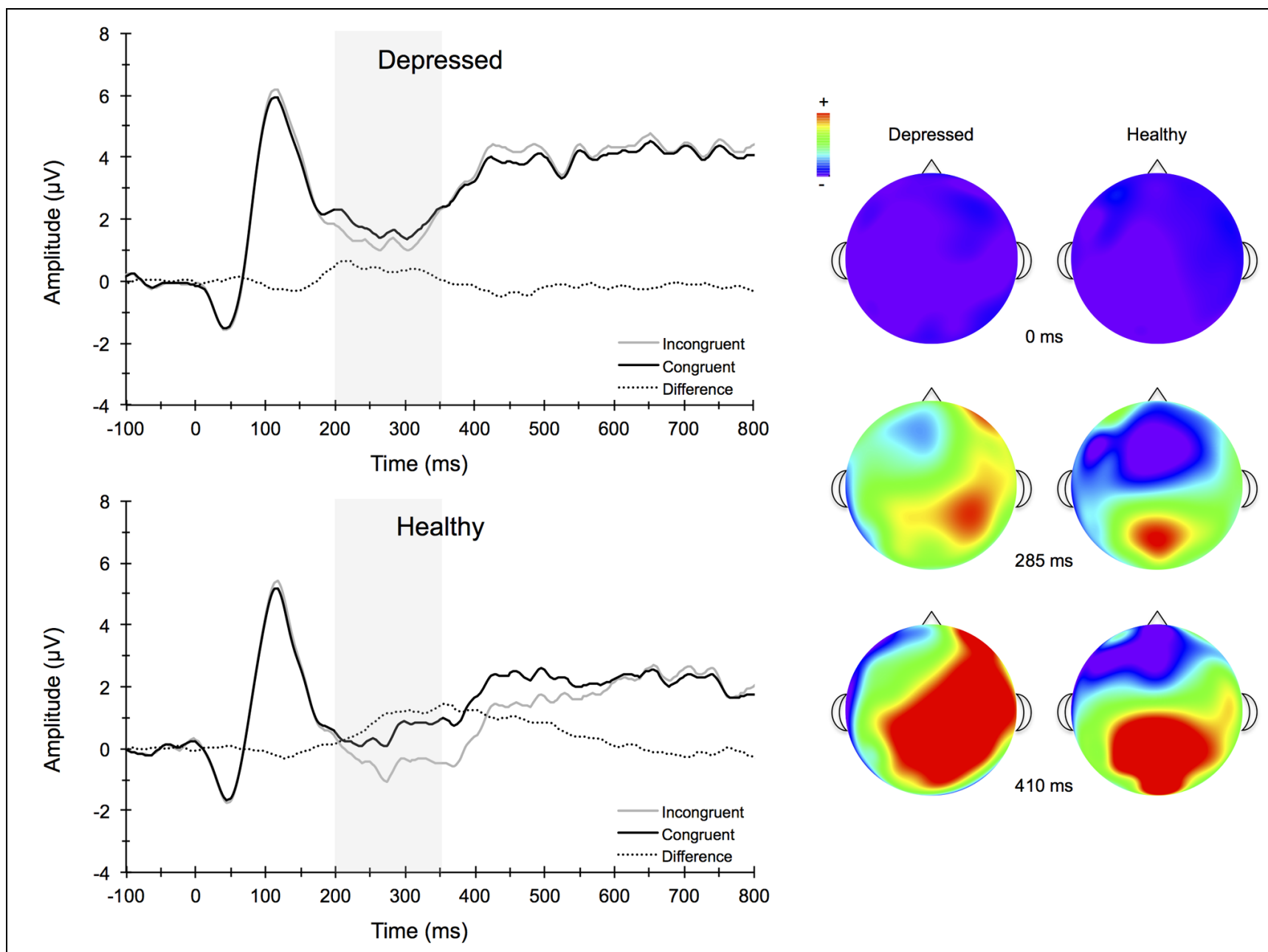

FIGURE 4 | Stimulus-locked grand average ERP waveforms for congruent (top left) and incongruent (bottom left) flanker conditions averaged across frontocentral midline electrode sites Fz, FCz, and Cz. Topographic scalp maps (right) collapsed across congruency for depressed and healthy participants.

Contrary to expectations, behavioral performance and P3 amplitudes for the AB task were similar among depressed and nondepressed individuals, suggesting preserved temporal dynamics of attentional processes and neural resource allocation during the $\mathrm{AB}$ task in MDD. The implications of these findings are discussed below.

First, similar to several previous studies (Krompinger and Simons, 2011; Clawson et al., 2013) we failed to observe any differences in behavioral performance measures between individuals with MDD and typical controls. Moreover, no significant correlations were found between self-reported rumination and accuracy or reaction time measures for either cognitive task. In contrast, although Holmes and Pizzagalli (2008) reported no difference in accuracy, they found significantly longer response times for MDD patients relative to controls for the more challenging incongruent Stroop task trials. The participants in this latter study were older than those used in our study or in these previous studies of cognitive control deficits in MDD (Krompinger and Simons, 2011; Clawson et al., 2013). Many of the participants in our study were also university students.
It is possible that select neurocognitive deficits in MDD are not observable using behavioral performance measures in such a young, otherwise high functioning population. One advantage of ERPs over behavioral measures is that they can provide information regarding the covert subset of neural processes that occur between stimulus engagement and motor response execution. Therefore, they may be more suitable to detecting any underlying impairment in conflict monitoring and attentional processes that may be present yet not observable through other measures. Future studies aimed at investigating the temporal sequence of cognitive deficits and MDD as well as any developmental variations in these neurocognitive processes are warranted.

Depressed individuals displayed lower N2 ERP amplitudes during the flanker task, a task requiring variable amounts of cognitive control. The ERP data suggested impairment in early conflict processing stages of information processing. This suggests that the MDD group recruited less cognitive control during task performance compared to healthy controls. Previous studies examining the N2 component in MDD have 


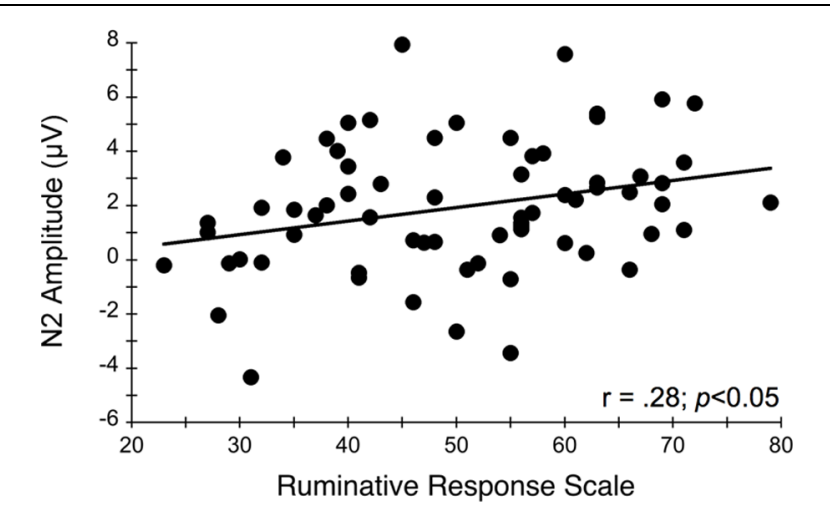

FIGURE 5 | Relationship between N2 amplitude averaged across frontocentral midline electrode sites $\mathrm{Fz}, \mathrm{FCz}$, and $\mathrm{Cz}$ and self-reported rumination levels during the flanker task. More positive N2 amplitudes are interpreted as an index of impaired conflict monitoring.

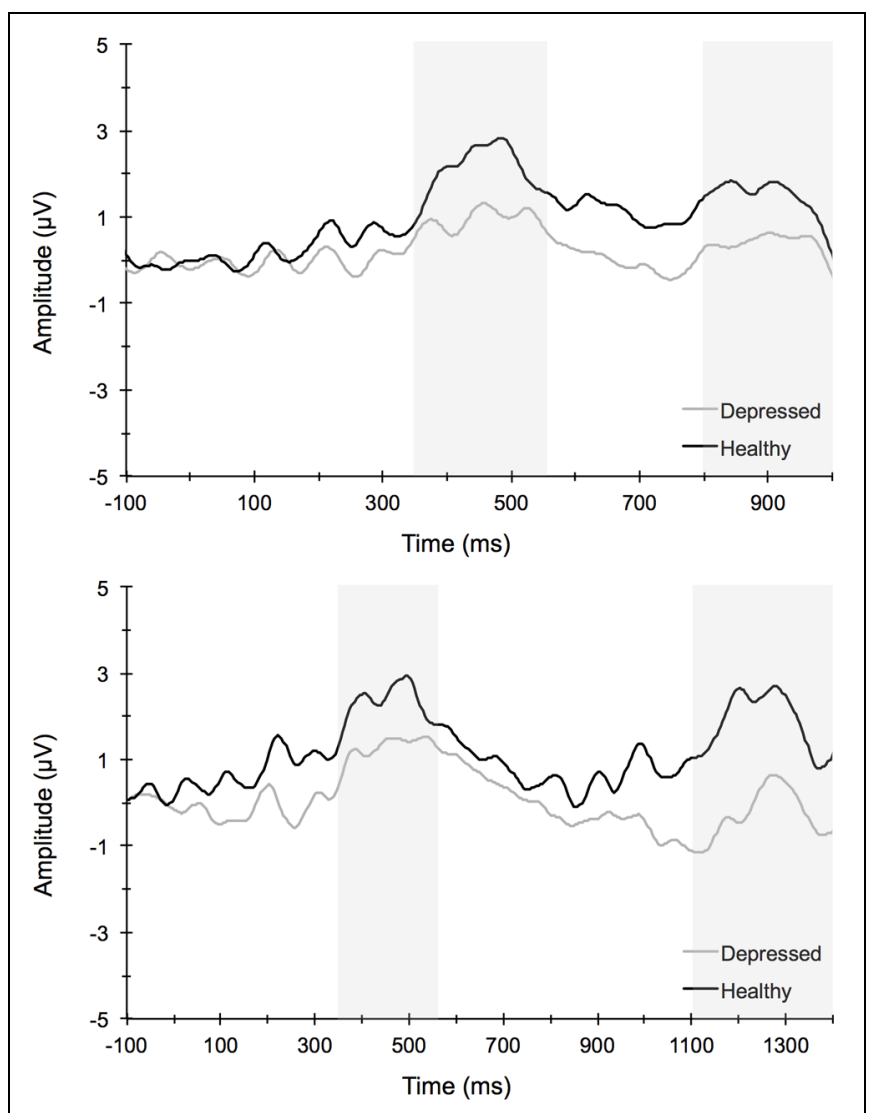

FIGURE 6 | Stimulus-locked grand average waveforms for short (top) and long (long) attentional blink trials averaged across centroparietal midline electrode sites $\mathrm{Cz}, \mathrm{CPz}$, and Pz.

resulted in mixed findings, and several recent studies have not found between group (MDD versus controls) differences in N2 amplitude (Ruchsow et al., 2008; Clawson et al., 2013). Clawson et al. (2013) examined N2 amplitudes in the context of conflict adaptation, wherein previous trial congruency influences current-trial performance through available cognitive control resources. Although no group differences were found, depressive symptoms assessed through the BDI-II were significantly correlated with N2 conflict adaptation scores. The authors noted that the relationship between symptoms of depression and reduced conflict adaptation processes may be dimensional rather than categorical in nature, and that individuals who experience levels of depression that fail to meet diagnostic thresholds may still evidence cognitive dysfunction, including those processes involved in conflict adaptation. In contrast, Mao et al. (2005) assessed an N2 component (labeled the N270 in their study) during a visual S1-S2 mismatch paradigm and found smaller N270 amplitude among the depressed patients compared to controls at frontal and parietal electrode sites. This finding was interpreted as evidence of impaired conflict processing, involving ACC and lateral PFC regions. Differences in the tasks used, clinical characteristics of the participants, and precise timing of the component amplitudes across studies may have resulted in the mixed findings in the literature. Future studies should incorporate tasks that are believed to be sensitive to both early and later stages of cognitive control processes to elucidate the precise temporal nature of dysfunction in MDD. Moreover, it will be important for future research to examine this relationship across a wider domain of depression severity to determine whether this relationship is stronger for more severely depressed individuals versus those with mild to moderate depression.

Several previous studies have also studied other ERP components associated with cognitive control processes in depressed patients using both emotional (Mitterschiffthaler et al., 2007; McNeely et al., 2008) and non-emotional (Holmes and Pizzagalli, 2008; Katz et al., 2010; Krompinger and Simons, 2011; Clawson et al., 2013) tasks. Using a Stroop task, Holmes and Pizzagalli (2008) found that individuals with MDD showed larger Stroop interference effects and reduced N2 and N450 amplitudes. The N450 component belongs to the conflict-monitoring family of ERPs and is believed to represent similar cognitive control processes related to conflict monitoring (i.e., N2), although it may not be as sensitive to conflict adaptation processes (Larson et al., 2014). Moreover, source localization analyses revealed reduced activation within dorsal ACC and left dorsolateral PFC regions $620 \mathrm{~ms}$ after stimulus presentation among MDD participants, and the reduced activation resulted primarily in response to incongruent trials (Holmes and Pizzagalli, 2008). Krompinger and Simons (2011) similarly found overall reduced Stroop N450 amplitudes in undergraduates with high BDI scores relative to those with lower BDI scores; however, a large Stroop congruency effect was found for the N450 for the high but not for the low depressive group, amid comparable behavioral task performance scores. This hyperactivation was also related to rumination and suggests that trait ruminators might over engage cognitive control processes, including the affective subdivisions of the ACC, in the process of performing at normative levels. It is also possible that depressed individuals have less efficient neuronal resources due to other psychological processes that occur during performance of the task, which may happen with trait ruminators. To examine this possibility, we assessed the 
correlation between individual differences in rumination and N2 amplitudes elicited by the flanker stimuli. We found that $\mathrm{N} 2$ amplitudes were significantly related to self-reported rumination levels, such that higher rumination scores were related to lower N2 amplitude. Thus, rumination appears to be associated with less efficient conflict monitoring resources used to attend to stimuli in the environment that may be unexpected and require the upregulation of cognitive control. This diminished cognitive control at the neurological level may partially explain why some depressed individuals have difficulty disengaging from negative environmental experiences and a diminished ability to reappraise situations to find positive perspectives about the situation (Troy et al., 2010). These findings are consistent with other studies, which report that clinically depressed individuals have difficulty inhibiting the emotional effects of negative content (Goeleven et al., 2006; Lau et al., 2007), even after the depression has remitted (Joormann, 2004; Joormann and Gotlib, 2007).

Deficits of cognitive control in depression could be caused by a number of neurobiological factors such as epigenetic influences, neurovascular changes, stress exposure, or environmental and social influences, among others. These influences likely interact to confer risk for MDD in particular and psychopathology more broadly. A recent meta-analysis of 193 structural neuroimaging studies across six diverse psychiatric diagnostic groups (schizophrenia, bipolar disorder, depression, addiction, obsessive-compulsive disorder, and anxiety) found gray matter loss in three specific brain regions across diagnostic categories: the dorsal anterior cingulate, right insula, and left insula (Goodkind et al., 2015). This finding was important not only in demonstrating a possible shared disrupted neural circuitry across diagnoses, but highlights the potential importance of executive functioning or cognitive control in these conditions. Others have previously noted important brain regions in depression (prefrontal cortex, hippocampus, and amygdala; Davidson et al., 2002), and, importantly, these structures also emerged as critical to depression in the metaanalysis (Goodkind et al., 2015). Depression may result in underlying neurobiological changes that in turn cause impairment in cognitive control (Snyder, 2013). The causal pathway may be explained by underlying impairments in cognitive control contributing to risk for or relapse of depressive episodes, possibly by contributing to an inability to inhibit feelings of frustration, helplessness, and low self-worth (Hammar and Ardal, 2009). As mentioned previously, there is a need for longitudinal studies to examine the directional links between cognitive control processes and depression at both a behavioral and neurobiological level.

A number of different attentional processes have been studied in relation to mood disorders and MDD (Hammar and Ardal, 2009; Lyche et al., 2011). Previous studies have indicated that the temporal dynamics of attentional processes can be influenced by demographic, lifestyle, or health factors, as reflected by the size of the $\mathrm{AB}$ as well as $\mathrm{P} 3$ amplitude (Martens et al., 2006; Slagter et al., 2007; Wu and Hillman, 2013), but how temporal dynamics of attention are affected by MDD is not well-understood. In the present study, we observed no group differences in attentional resources devoted to the $\mathrm{AB}$ task in participants with MDD. Specifically, no significant differences in the magnitude of the $\mathrm{AB}$ or $\mathrm{P} 3$ amplitude were observed between depressed and healthy groups. It is possible that individuals with depression can maintain attention through basic attentional tasks (e.g., simple organization tasks), but have more difficulty as the tasks require greater response monitoring or conflict (e.g., cognitive evaluation, aspects of social engagement). It is important in future research to examine the temporal sequence between MDD and conflict monitoring aspects of cognitive control. Our results suggest the possibility that an initial target of treatment in MDD should be the reduction of rumination.

While these data suggest impaired conflict monitoring in MDD, several limitations should be noted. First, the current sample size was relatively small, which may have limited power in detecting group differences in subtle attentional processes. Second, although group differences emerged in ERPs that were elicited by the flanker task, we did not observe statistically significant differences in behavioral task performance between depressed and healthy participants. We also did not find any significant correlations between N2 and P3 amplitudes and task performance measures. Previous studies have shown a relation between $\mathrm{N} 2$ amplitudes and reaction time (Yeung et al., 2004; Yeung and Nieuwenhuis, 2009; Clayson and Larson, 2011), suggesting that the degree of conflict as measured my $\mathrm{N} 2$ amplitude is reflected in impaired behavioral performance. It is possible that our version of the flanker task was not demanding enough to detect behavioral differences by depression status. Another possible explanation may be that our behavioral tasks did not involve a negative valence component, which may have activated depression symptomology more than the neutral behavioral stimuli used in this study. Further, it is possible that the MDD sample, consisting of enrolled undergraduate students, was functioning at a sufficiently high cognitive level to overcome potential neurocognitive limitations on the tasks employed. As mentioned previously, the precise temporal resolution of ERPs provides a more sensitive approach for detecting cognitive deficits and their underlying neurophysiological mechanisms. Although we did not source-localize our ERP components, the nature of the cognitive tasks and the ERP findings nonetheless allow us to draw comparisons to those observed in other ERP studies examining cognitive control processes.

In spite of these limitations, the present findings suggest a potential link between conflict monitoring processes and rumination in MDD. This study represents an initial step in developing a more comprehensive understanding of depression by integrating neural and cognitive models of MDD. The ERP data combined with previous source localization and fMRI studies suggest dysregulation within anterior cingulate and prefrontal brain regions in MDD (Holmes and Pizzagalli, 2008; Pizzagalli, 2011). Given these and related data, it is important to develop clinical interventions which increase the neuronal response that underlies conflict monitoring processes and reduce the maladaptive levels of rumination that often are observed in individuals with MDD. 


\section{Acknowledgments}

This work was funded by The Charles and Johanna Busch Memorial Fund at Rutgers, The State University of New Jersey to BA and ES. This work was also supported by National Institutes of Health grants K02AA000325 and K24AA021778,

\section{References}

American Psychiatric Association. (1994). Diagnostic and Statistical Manual of Mental Disorders. Washington, DC: American Psychiatric Association.

American Psychiatric Association. (2000). Diagnostic and Statistical Manual of Mental Disorders. Washington, DC: American Psychiatric Association.

Aron, A. R. (2007). The neural basis of inhibition in cognitive control. Neuroscientist 13, 214-228. doi: 10.1177/1073858407299288

Austin, M. P., Mitchell, P., and Goodwin, G. M. (2001). Cognitive deficits in depression: possible implications for functional neuropathology. Br. J. Psychiatry 178, 200-206. doi: 10.1192/bjp.178.3.200

Beck, A. T., Steer, R. A., and Brown, G. K. (1996). Manual for the Beck Depression Inventory-II. San Antonio, TX: Psychological Corporation.

Beck, A. T., Ward, C. H., Mendelson, M., Mock, J., and Erbaugh, J. (1961). An inventory for measuring depression. Arch. Gen. Psychiatry 4, 561-571. doi: 10.1001/archpsyc.1961.01710120031004

Bertrand, O., Perrin, F., and Pernier, J. (1985). A theoretical justification of the average reference in topographic evoked potential studies. Electroencephalogr. Clin. Neurophysiol. 62, 462-464. doi: 10.1016/0168-5597(85)90058-9

Botvinick, M. M., Braver, T. S., Barch, D. M., Carter, C. S., and Cohen, J. D. (2001), Conflict monitoring and cognitive control. Psychol. Rev. 108, 624-652. doi: 10.1037/0033-295X.108.3.624

Botvinick, M. M., Cohen, J. D., and Carter, C. S. (2004). Conflict monitoring and anterior cingulate cortex: an update. Trends Cogn. Sci. Regul. Ed. 8, 539-546. doi: 10.1016/j.tics.2004.10.003

Botvinick, M., Nystrom, L. E., Fissell, K., Carter, C. S., and Cohen, J. D. (1999). Conflict monitoring versus selection-for-action in anterior cingulate cortex. Nature 402, 179-181. doi: 10.1038/46035

Broadbent, D. E., and Broadbent, M. H. (1987). From detection to identification: response to multiple targets in rapid serial visual presentation. Percept. Psychophys. 42, 105-113. doi: 10.3758/BF03210498

Bruder, G. E., Kayser, J., and Tenke, C. E. (2012). "Event-related brain potentials in depression: clinical, cognitive, and neurophysiologic implications," in The Oxford Handbook of Event-Related Potential Components, eds S. J. Luck and E. S. Kappenman (New York, NY: Oxford University Press).

Chatrian, G. E., Lettich, E., and Nelson, P. L. (1988). Modified nomenclature for the "10\%" electrode system. J. Clin. Neurophysiol. 5, 183-186. doi: 10.1097/00004691-198804000-00005

Clawson, A., Clayson, P. E., and Larson, M. J. (2013). Cognitive control adjustments and conflict adaptation in major depressive disorder. Psychophysiology 50, 711-721. doi: 10.1111/psyp.12066

Clayson, P. E., Baldwin, S. A., and Larson, M. J. (2013). How does noise affect amplitude and latency measurement of event-related potentials (ERPs)? A methodological critique and simulation study. Psychophysiology 50, 174-186. doi: $10.1111 /$ psyp. 12001

Clayson, P. E., and Larson, M. J. (2011). Effects of repetition priming on electrophysiological and behavioral indices of conflict adaptation and cognitive control. Psychophysiology 48, 1621-1630. doi: 10.1111/j.14698986.2011.01265.x

Cohen, J. (1973). Eta-squared and partial eta-squared in fixed factor ANOVA designs. Educ. Psychol. Meas. 33, 107-112. doi: 10.1177/001316447303300111

Cohen, R., Lohr, I., Paul, R., and Boland, R. (2001). Impairments of attention and effort among patients with major affective disorders. J. Neuropsychiatry Clin. Neurosci. 13, 385-395. doi: 10.1176/jnp.13.3.385

Davidson, R. J., Pizzagalli, D., Nitschke, J. B., and Putnam, K. (2002). Depression: perspectives from affective neuroscience. Annu. Rev. Psychol. 53, 545-574. doi: 10.1146/annurev.psych.53.100901.135148

de Bruijn, E. R., Sabbe, B. G., Hulstijn, W., Ruigt, G. S., and Verkes, R. J. (2006). Effects of antipsychotic and antidepressant drugs on and contract HHSN275201000003C to $\mathrm{MB}$ and $\mathrm{NIH}$ grant K01AA017473 to JB. The authors thank Michael J. Larson for offering important suggestions to a previous version of the paper. We also gratefully acknowledge Rutgers University Counseling and Psychiatric Services (CAPS) for assistance in participant recruitment.

action monitoring in healthy volunteers. Brain Res. 1105, 122-129. doi: 10.1016/j.brainres.2006.01.006

Dickter, C. L., and Bartholow, B. D. (2010). Ingroup categorization and response conflict: interactive effects of target race, flanker compatibility, and infrequency on N2 amplitude. Psychophysiology 47, 596-601. doi: 10.1111/j.14698986.2010.00963.x

Donaldson, C., Lam, D., and Mathews, A. (2007). Rumination and attention in major depression. Behav. Res. Ther. 45, 2664-2678. doi: 10.1016/j.brat.2007.07.002

Donchin, E., and Coles, M. G. (1988). Is the P300 component a manifestation of context updating? Behav. Brain Sci. 11, 357-374. doi: $10.1017 / \mathrm{S} 0140525 \mathrm{X} 00058027$

Dux, P. E., and Marois, R. (2009). The attentional blink: a review of data and theory. Atten. Percept. Psychophys. 71, 1683-1700. doi: 10.3758/APP.71.8.1683

Eriksen, B. A., and Eriksen, C. W. (1974). Effects of noise letters upon the identification of a target letter in a nonsearch task. Atten. Percept. Psychophys. 16, 143-149. doi: 10.3758/BF03203267

Ferree, T. C., Luu, P., Russell, G. S., and Tucker, D. M. (2001). Scalp electrode impedance, infection risk, and EEG data quality. Clin. Neurophysiol. 112, 536-544. doi: 10.1016/S1388-2457(00)00533-2

First, M. B., Spitzer, R. L., Gibbon, M., and Williams, J. B. (1995). The structured clinical interview for DSM-III-R personality disorders (SCID-II). Part I: description. J. Pers. Disord. 9, 83-91. doi: 10.1521/pedi.1995.9.2.83

Folstein, J. R., and Van Petten, C. (2008). Influence of cognitive control and mismatch on the N2 component of the ERP: a review. Psychophysiology 45, $152-170$.

Gehring, W. J., Himle, J., and Nisenson, L. G. (2000). Action-monitoring dysfunction in obsessive-compulsive disorder. Psychol. Sci. 11, 1-6. doi: 10.1111/14679280.00206

Goeleven, E., De Raedt, R., Baert, S., and Koster, E. H. (2006). Deficient inhibition of emotional information in depression. J. Affect. Disord. 93, 149-157. doi: 10.1016/j.jad.2006.03.007

Goodkind, M., Eickhoff, S. B., Oathes, D. J., Jiang, Y., Chang, A., Jones-Hagata, L. B., et al. (2015). Identification of a common neurobiological substrate for mental illness. JAMA Psychiatry 72, 305-315. doi: 10.1001/jamapsychiatry.2014.2206

Gotlib, I. H., and Joormann, J. (2010). Cognition and depression: current status and future directions. Annu. Rev. Clin. Psychol. 6, 285-312. doi: 10.1146/annurev.clinpsy.121208.131305

Hajcak, G., Franklin, M. E., Foa, E. B., and Simons, R. F. (2008). Increased errorrelated brain activity in pediatric obsessive-compulsive disorder before and after treatment. Am. J. Psychiatry 165, 116-123. doi: 10.1176/appi.ajp.2007.07 010143

Hammar, A., and Ardal, G. (2009). Cognitive functioning in major depression-a summary. Front. Hum. Neurosci. 3:26. doi: 10.3389/neuro.09.026.2009

Hammar, A., Lund, A., and Hugdahl, K. (2003). Selective impairment in effortful information processing in major depression. J. Int. Neuropsychol. Soc. 9, 954-959. doi: 10.1017/S1355617703960152

Hedges, L. V. (1981). Distribution theory for Glass's estimator of effect size and related estimators. J. Educ. Stat. 6, 107-128. doi: 10.2307/1164588

Hollingsworth, D. E., Mcauliffe, S. P., and Knowlton, B. J. (2001). Temporal allocation of visual attention in adult attention deficit hyperactivity disorder. J. Cogn. Neurosci. 13, 298-305. doi: 10.1162/08989290151137359

Holmes, A. J., and Pizzagalli, D. A. (2008). Response conflict and frontocingulate dysfunction in unmedicated participants with major depression Neuropsychologia 46, 2904-2913. doi: 10.1016/j.neuropsychologia.2008.05.028

Hommel, B., Kessler, K., Schmitz, F., Gross, J., Akyürek, E., Shapiro, K., et al. (2006). How the brain blinks: towards a neurocognitive model of the attentional blink. Psychol. Res. 70, 425-435. doi: 10.1007/s00426-005-0009-3 
Husain, M., and Rorden, C. (2003). Non-spatially lateralized mechanisms in hemispatial neglect. Nat. Rev. Neurosci. 4, 26-36. doi: 10.1038/n rn1005

Husain, M., Shapiro, K., Martin, J., and Kennard, C. (1997). Abnormal temporal dynamics of visual attention in spatial neglect patients. Nature 385, 154-156. doi: $10.1038 / 385154 \mathrm{a} 0$

Jones, J. E., Hermann, B. P., Barry, J. J., Gilliam, F., Kanner, A. M., and Meador, K. J. (2005). Clinical assessment of Axis I psychiatric morbidity in chronic epilepsy: a multicenter investigation. J. Neuropsychiatry Clin. Neurosci. 17, 172-179. doi: 10.1176/jnp.17.2.172

Joormann, J. (2004). Attentional bias in dysphoria: the role of inhibitory processes. Cogn. Emot. 18, 125-147. doi: 10.1080/02699930244000480

Joormann, J., Dkane, M., and Gotlib, I. H. (2006). Adaptive and maladaptive components of rumination? Diagnostic specificity and relation to depressive biases. Behav. Ther. 37, 269-280. doi: 10.1016/j.beth.2006.01.002

Joormann, J., and Gotlib, I. H. (2007). Selective attention to emotional faces following recovery from depression. J. Abnorm. Psychol. 116, 80-85. doi: 10.1037/0021-843X.116.1.80

Kaiser, S., Unger, J., Kiefer, M., Markela, J., Mundt, C., and Weisbrod, M. (2003). Executive control deficit in depression: event-related potentials in a Go/Nogo task. Psychiatry Res. 122, 169-184. doi: 10.1016/S0925-4927(03)00004-0

Katz, R., De Sanctis, P., Mahoney, J. R., Sehatpour, P., Murphy, C. F., Gomez-Ramirez, M., et al. (2010). Cognitive control in late-life depression: response inhibition deficits and dysfunction of the anterior cingulate cortex. Am. J. Geriatr. Psychiatry 18, 1017-1025. doi: 10.1097/JGP.0b013e3181 d695f2

Keil, A., Debener, S., Gratton, G., Junghofer, M., Kappenman, E. S., Luck, S. J., et al. (2014). Committee report: publication guidelines and recommendations for studies using electroencephalography and magnetoencephalography. Psychophysiology 51, 1-21. doi: 10.1111/psyp.12147

Kessler, R. C., Berglund, P., Demler, O., Jin, R., Merikangas, K. R., and Walters, E. E. (2005). Lifetime prevalence and age-of-onset distributions of DSM-IV disorders in the National Comorbidity Survey Replication. Arch. Gen. Psychiatry 62, 593-602. doi: 10.1001/archpsyc.62.6.593

Krompinger, J. W., and Simons, R. F. (2011). Cognitive inefficiency in depressive undergraduates: stroop processing and ERPs. Biol. Psychol. 86, 239-246. doi: 10.1016/j.biopsycho.2010.12.004

Lahar, C. J., Isaak, M. I., and Mcarthur, A. D. (2001). Age differences in the magnitude of the attentional blink. Aging Neuropsychol. Cogn. 8, 149-159. doi: 10.1076/anec.8.2.149.842

Larson, M. J., Clayson, P. E., and Clawson, A. (2014). Making sense of all the conflict: a theoretical review and critique of conflict-related ERPs. Int. J. Psychophysiol. 93, 283-297. doi: 10.1016/j.ijpsycho.2014.06.007

Lau, M. A., Christensen, B. K., Hawley, L. L., Gemar, M. S., and Segal, Z. V. (2007). Inhibitory deficits for negative information in persons with major depressive disorder. Psychol. Med. 37, 1249-1259. doi: 10.1017/S0033291707000530

Lecrubier, Y., Sheehan, D., Weiller, E., Amorim, P., Bonora, I., Harnett Sheehan, K., et al. (1997). The mini international neuropsychiatric interview (MINI). A short diagnostic structured interview: reliability and validity according to the CIDI. Eur. Psychiatry 12, 224-231. doi: 10.1016/S0924-9338(97)83296-8

Lemelin, S., Baruch, P., Vincent, A., Everett, J., and Vincent, P. (1997). Distractibility and processing resource deficit in major depression. Evidence for two deficient attentional processing models. J. Nerv. Ment. Dis. 185, 542-548. doi: 10.1097/00005053-199709000-00002

Li, C. S., Lin, W. H., Chang, H. L., and Hung, Y. W. (2004). A psychophysical measure of attention deficit in children with attention-deficit/hyperactivity disorder. J. Abnorm. Psychol. 113, 228-236. doi: 10.1037/0021-843X.113.2.228

Luck, S. J. (2014). An Introduction to the Event-Related Potential Technique. Cambridge, MA: The MIT Press.

Luck, S. J., Vogel, E. K., and Shapiro, K. L. (1996). Word meanings can be accessed but not reported during the attentional blink. Nature 383, 616-618. doi: $10.1038 / 383616 \mathrm{a} 0$

Luck, S. J., Woodman, G. F., and Vogel, E. K. (2000). Event-related potential studies of attention. Trends Cogn. Sci. Regul. Ed. 4, 432-440. doi: 10.1016/S13646613(00)01545-X

Lyche, P., Jonassen, R., Stiles, T., Ulleberg, P., and Landrø, N. (2011). Attentional functions in major depressive disorders with and without comorbid anxiety. Arch. Clin. Neuropsychol. 26, 38-47. doi: 10.1093/arclin/acq095
Maciokas, J. B., and Crognale, M. A. (2003). Cognitive and attentional changes with age: evidence from attentional blink deficits. Exp. Aging Res. 29, 137-153. doi: 10.1080/03610730303715

Mao, W., Wang, Y., and Wang, D. (2005). Cognitive impairment in major depressive disorder revealed by event-related potential N270. Clin. EEG Neurosci. 36, 9-14. doi: 10.1177/155005940503600104

Marois, R., and Ivanoff, J. (2005). Capacity limits of information processing in the brain. Trends Cogn. Sci. Regul. Ed. 9, 296-305. doi: 10.1016/j.tics.2005.04.010

Martens, S., Munneke, J., Smid, H., and Johnson, A. (2006). Quick minds don't blink: electrophysiological correlates of individual differences in attentional selection. J. Cogn. Neurosci. 18, 1423-1438. doi: 10.1162/jocn.2006.18.9.1423

Martens, S., Wolters, G., and Van Raamsdonk, M. (2002). Blinks of the mind: memory effects of attentional processes. J. Exp. Psychol. Hum. Percept. Perform. 28, 1275-1287. doi: 10.1037/0096-1523.28.6.1275

Martens, S., and Wyble, B. (2010). The attentional blink: past, present, and future of a blind spot in perceptual awareness. Neurosci. Biobehav. Rev. 34, 947-957. doi: 10.1016/j.neubiorev.2009.12.005

Mathers, C. D., Fat, D. M., and Boerma, J. (2008). The Global Burden of Disease: 2004 Update. Geneva: World Health Organization.

McLaughlin, K. A., Borkovec, T. D., and Sibrava, N. J. (2007). The effects of worry and rumination on affect states and cognitive activity. Behav. Ther. 38, 23-38. doi: 10.1016/j.beth.2006.03.003

McNeely, H. E., Lau, M. A., Christensen, B. K., and Alain, C. (2008). Neurophysiological evidence of cognitive inhibition anomalies in persons with major depressive disorder. Clin. Neurophysiol. 119, 1578-1589. doi: 10.1016/j.clinph.2008.03.031

Miller, E. K. (2000). The prefontral cortex and cognitive control. Nat. Rev. Neurosci. 1, 59-65. doi: 10.1038/35036228

Miller, E. K., and Cohen, J. D. (2001). An integrative theory of prefrontal cortex function. Annu. Rev. Neurosci. 24, 167-202. doi: 10.1146/annurev.neuro.24.1.167

Mitterschiffthaler, M. T., Fu, C. H., Dalton, J. A., Andrew, C. M., and Williams, S. C. (2007). A functional MRI study of happy and sad affective states induced by classical music. Hum. Brain Mapp. 28, 1150-1162. doi: 10.1002/hbm.20337

Nolen-Hoeksema, S., Larson, J., and Grayson, C. (1999). Explaining the gender difference in depressive symptoms. J. Pers. Soc. Psychol. 77, 1061-1072. doi: 10.1037/0022-3514.77.5.1061

Nolen-Hoeksema, S., Wisco, B. E., and Lyubomirsky, S. (2008). Rethinking rumination. Perspect. Psychol. Sci. 3, 400-424. doi: 10.1111/j.1745-6924.2008.00088.x

Ottowitz, W. E., Dougherty, D. D., and Savage, C. R. (2002). The neural network basis for abnormalities of attention and executive function in major depressive disorder: implications for application of the medical disease model to psychiatric disorders. Harv. Rev. Psychiatry 10, 86-99. doi: 10.1080/10673220216210

Pizzagalli, D. A. (2011). Frontocingulate dysfunction in depression: toward biomarkers of treatment response. Neuropsychopharmacology 36, 183-206. doi: 10.1038/npp.2010.166

Polich, J. (2007). Updating P300: an integrative theory of P3a and P3b. Clin. Neurophysiol. 118, 2128-2148. doi: 10.1016/j.clinph.2007.04.019

Ravnkilde, B., Videbech, P., Clemmensen, K., Egander, A., Rasmussen, N. A., and Rosenberg, R. (2002). Cognitive deficits in major depression. Scand. J. Psychol. 43, 239-251. doi: 10.1111/1467-9450.00292

Raymond, J. E., Shapiro, K. L., and Arnell, K. M. (1992). Temporary suppression of visual processing in an RSVP task: an attentional blink? J. Exp. Psychol. Hum. Percept. Perform. 18, 849-860. doi: 10.1037/0096-1523.18.3.849

Ruchsow, M., Groen, G., Kiefer, M., Buchheim, A., Walter, H., Martius, P., et al. (2008). Response inhibition in borderline personality disorder: eventrelated potentials in a Go/Nogo task. J. Neural Transm. 115, 127-133. doi: 10.1007/s00702-007-0819-0

Shapiro, K. L., Raymond, J. E., and Arnell, K. M. (1997). The attentional blink. Trends Cogn. Sci. Regul. Ed. 1, 291-296. doi: 10.1016/S1364-6613(97)01094-2

Sheehan, D., Lecrubier, Y., Harnett Sheehan, K., Janavs, J., Weiller, E., Keskiner, A., et al. (1997). The validity of the Mini International Neuropsychiatric Interview (MINI) according to the SCID-P and its reliability. Eur. Psychiatry 12, 232-241. doi: 10.1016/S0924-9338(97)83297-X

Sheehan, D. V., Lecrubier, Y., Sheehan, K. H., Amorim, P., Janavs, J., Weiller, E., et al. (1998). The Mini-International Neuropsychiatric Interview (M.I.N.I.): the development and validation of a structured diagnostic psychiatric interview for DSM-IV and ICD-10. J. Clin. Psychiatry 59, 22-33. 
Slagter, H. A., Lutz, A., Greischar, L. L., Francis, A. D., Nieuwenhuis, S., Davis, J. M., et al. (2007). Mental training affects distribution of limited brain resources. PLoS Biol. 5:e138. doi: 10.1371/journal.pbio.0050138

Snyder, H. R. (2013). Major depressive disorder is associated with broad impairments on neuropsychological measures of executive function: a meta-analysis and review. Psychol. Bull. 139, 81-132. doi: 10.1037/a0028727

Tillman, C. M., and Wiens, S. (2011). Behavioral and ERP indices of response conflict in Stroop and flanker tasks. Psychophysiology 48, 1405-1411. doi: 10.1111/j.1469-8986.2011.01203.x

Troy, A. S., Wilhelm, F. H., Shallcross, A. J., and Mauss, I. B. (2010). Seeing the silver lining: cognitive reappraisal ability moderates the relationship between stress and depressive symptoms. Emotion 10, 783-795. doi: 10.1037/a00 20262

Tucker, D. M., Liotti, M., Potts, G. F., Russell, G. S., and Posner, M. I. (1994). Spatiotemporal analysis of brain electrical fields. Hum. Brain Mapp. 1, 134-152. doi: 10.1002/hbm.460010206

Vanderhasselt, M. A., De Raedt, R., Dillon, D. G., Dutra, S. J., Brooks, N., and Pizzagalli, D. A. (2012). Decreased cognitive control in response to negative information in patients with remitted depression: an event-related potential study. J. Psychiatry Neurosci. 37, 250-258. doi: 10.1503/jpn.110089

van Veen, V., and Carter, C. S. (2002). The anterior cingulate as a conflict monitor: fMRI and ERP studies. Physiol. Behav. 77, 477-482. doi: 10.1016/S00319384(02)00930-7

Veiel, H. O. (1997). A preliminary profile of neuropsychological deficits associated with major depression. J. Clin. Exp. Neuropsychol. 19, 587-603. doi: 10.1080/01688639708403745

Wagner, G., Sinsel, E., Sobanski, T., Kohler, S., Marinou, V., Mentzel, H. J., et al. (2006). Cortical inefficiency in patients with unipolar depression: an event-related FMRI study with the Stroop task. Biol. Psychiatry 59, 958-965. doi: 10.1016/j.biopsych.2005.10.025

Whitmer, A. J., and Banich, M. T. (2007). Inhibition versus switching deficits in different forms of rumination. Psychol. Sci. 18, 546-553. doi: 10.1111/j.14679280.2007.01936.x

Wu, C. T., and Hillman, C. H. (2013). Aerobic fitness and the attentional blink in preadolescent children. Neuropsychology 27, 642-653. doi: 10.1037/a0034025

Yeung, N., Botvinick, M. M., and Cohen, J. D. (2004). The neural basis of error detection: conflict monitoring and the error-related negativity. Psychol. Rev. 111, 931-959. doi: 10.1037/0033-295X.111.4.931

Yeung, N., and Nieuwenhuis, S. (2009). Dissociating response conflict and error likelihood in anterior cingulate cortex. J. Neurosci. 29, 14506-14510. doi: 10.1523/JNEUROSCI.3615-09.2009

Zakzanis, K. K., Leach, L., and Kaplan, E. (1998). On the nature and pattern of neurocognitive function in major depressive disorder. Neuropsychiatry Neuropsychol. Behav. Neurol. 11, 111-119.

Conflict of Interest Statement: The authors declare that the research was conducted in the absence of any commercial or financial relationships that could be construed as a potential conflict of interest.

Copyright (c) 2015 Alderman, Olson, Bates, Selby, Buckman, Brush, Panza, Kranzler, Eddie and Shors. This is an open-access article distributed under the terms of the Creative Commons Attribution License (CC BY). The use, distribution or reproduction in other forums is permitted, provided the original author(s) or licensor are credited and that the original publication in this journal is cited, in accordance with accepted academic practice. No use, distribution or reproduction is permitted which does not comply with these terms. 